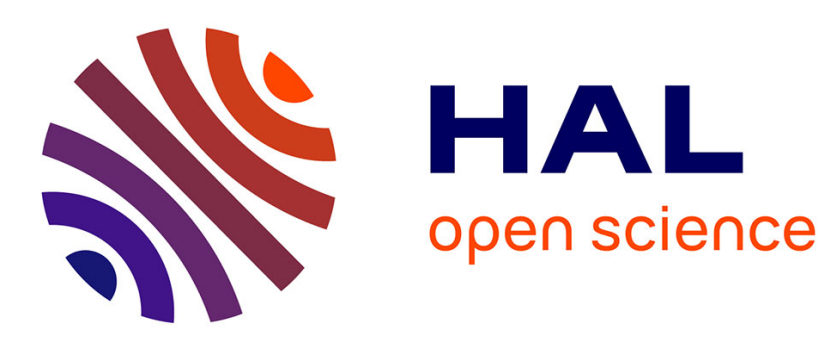

\title{
The effect of the Marangoni motion in the laser excitation of capillary waves
}

Al. Kolomenskii, H. Schuessler

\section{To cite this version:}

Al. Kolomenskii, H. Schuessler. The effect of the Marangoni motion in the laser excitation of capillary waves. Journal de Physique IV Proceedings, 1994, 04 (C7), pp.C7-753-C7-755. 10.1051/jp4:19947177 . jpa-00253238

\section{HAL Id: jpa-00253238 https://hal.science/jpa-00253238}

Submitted on 1 Jan 1994

HAL is a multi-disciplinary open access archive for the deposit and dissemination of scientific research documents, whether they are published or not. The documents may come from teaching and research institutions in France or abroad, or from public or private research centers.
L'archive ouverte pluridisciplinaire $\mathbf{H A L}$, est destinée au dépôt et à la diffusion de documents scientifiques de niveau recherche, publiés ou non, émanant des établissements d'enseignement et de recherche français ou étrangers, des laboratoires publics ou privés. 


\title{
The effect of the Marangoni motion in the laser excitation of capillary waves
}

\author{
Al.A. Kolomenskii (1) and H.A. Schuessler \\ Department of Physics, Texas A\&M University, College Station, TX 77843-4242, U.S.A.
}

\begin{abstract}
Under the action of a periodically modulated laser beam the development of a convective liquid motion due to creation of surface tension gradients counteracts the heat conductivity flux. This autoblocking effect manifests itself in the abrupt changes of the phase and the amplitude of the excited capillary wave.
\end{abstract}

\section{INTRODUCTION}

When a laser beam is incident on an absorbing liquid a deformation of the surface can be observed at the focal spot [1-3]. At moderate laser intensities of about several $\mathrm{W} / \mathrm{cm}^{2}$ this deformation was shown to be the result of the development of liquid motion [4]. The reason is that the heating of a liquid surface leads to the creation of surface tension gradients which in turn launch the liquid flow producing the so called Marangoni motion. In the case that a modulated cw laser beam is used, periodical perturbations of the liquid surface arise, which at frequencies larger than about $10 \mathrm{~Hz}$ propagate along the surface in the form of capillary waves. The excitation of the capillary waves by a modulated laser beam has been observed previously [2]. However this is the first time that the detailed mechanism of laser induced capillary wave generation is being studied. In particular the determination of the dependence of the capillary wave amplitude on the laser intensity is of interest. So far the existing theory is incomplete [5] since it does not take into accountthe development of the liquid motion. In the present work we use a wide range of laser intensities and demonstrate that already at moderate intensities surface deformation with Marangoni motion is a dominant excitation mechanism leading to abrupt changes in the capillary wave amplitude and phase.

\section{EXPERIMENTAL APPARATUS}

In the experiments an $\mathrm{Ar}^{+}$laser beam was on-off modulated with a stabilized chopper and was focused on the surface of a strongly absorbing dye solution (LDS 751 dissolved in ethylene glycol at a concentration of $1.25 \mathrm{~g} / \mathrm{L}$ ). The optical absorption at the laser wavelength of $\lambda=515 \mathrm{~nm}$ was measured to be $\alpha=70 \mathrm{~cm}^{-1}$. The capillary waves and the 


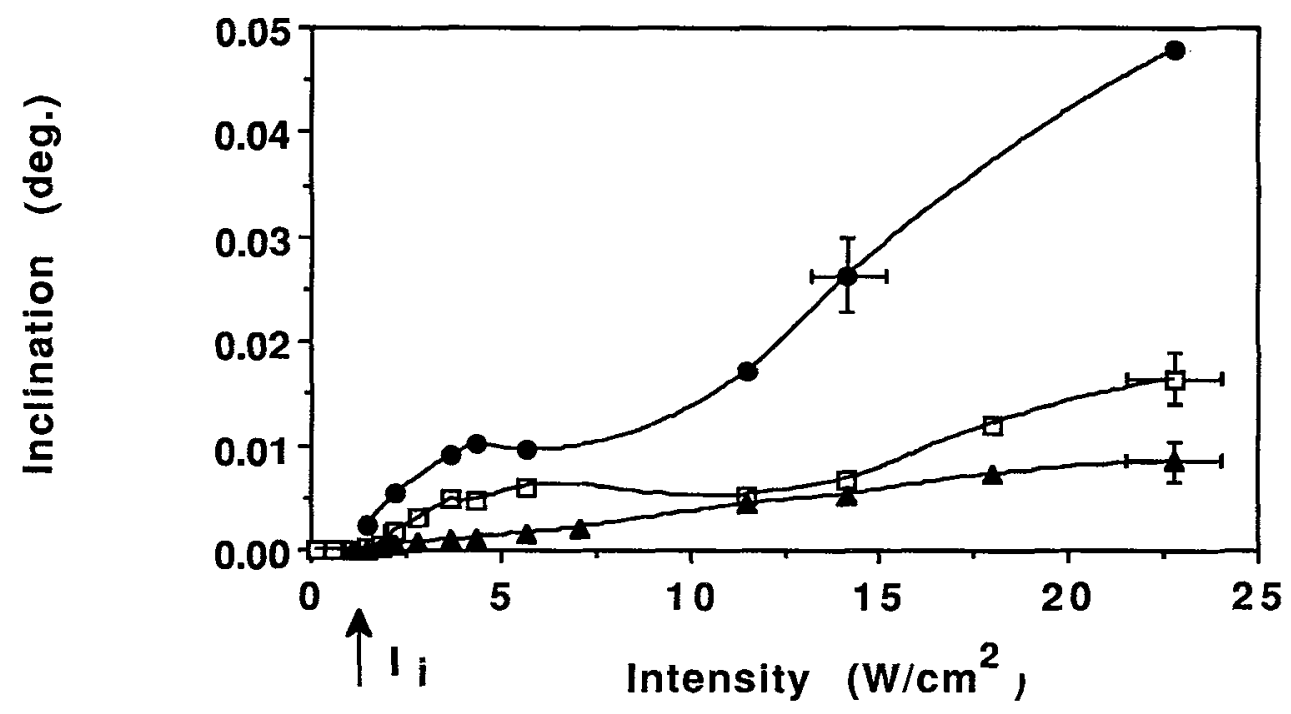

Fig. 1. Dependence of the signal of the first harmonic of the capillary wave for various modulation frequencies; (a) $40 \mathrm{~Hz},(\boldsymbol{\Delta}) 60 \mathrm{~Hz}$; (•) signal of the average surface deformation.

average surface deformations were registered by the deflection of a probe He-Ne laser beam using a position sensitive photodiode. The signal was observed with an oscillopcope and a lock-in amplifier.

\section{RESULTS}

In our experiment we measure the changes of the deflection angle of the probe beam reflecting off the observation point as the capillary wave passes through. The sensitivity of the registration scheme for surface inclinations of the liquid was about $80 \mathrm{~V} /$ degree. Fig. 1 depicts the observed signal amplitude versus laser intensity. The radius of the focal spot was $a=0.7 \mathrm{~mm}$, and the observation point monitored by the probe beam was a distance $d=5 \mathrm{~mm}$ away from the focal spot. At low intensities the signal of the capillary waves shows linear behavior [5]. However at an intensity of about $\mathrm{I}_{\mathrm{i}}=1.3 \mathrm{~W} / \mathrm{cm}^{2}$ an abrupt increase in the capillary wave signal occurs together with an increase of the average surface deformation signal. This is the threshold intensity for the onset of Marangoni

motion. For laser intensities between $1.5<\mathrm{I}<2.5 \mathrm{~W} / \mathrm{cm}^{2}$ a change of the phase of the capillary wave signal of about 80 degrees (for $\mathrm{f}=40 \mathrm{~Hz}$ ) was also observed. Similar results were observed under a variety of different experimental conditions when varying the radius of the focal spot between $a=0.5$ and $0.7 \mathrm{~mm}$, the depth of the liquid layer between $\mathrm{h}=2$ and 14 $\mathrm{mm}$, and the modulation frequency between $\mathrm{f}=16$ and $60 \mathrm{~Hz}$.

\section{THEORY}

A detailed nonlinear model of the Marangoni motion was developed taking into account also the pulsations of this motion due to the modulation of the laser beam. According to this model a sudden increase of the temperature relaxation time near the threshold intensity $\mathrm{I}_{i}$ takes place. At this intensity the heat flux from the absorption region due to the heat 
conductivity of the liquid is reduced by a backward heat transfer caused by the occurrence of a counterflow of the liquid. Such an autoblocking effect of the heat flux in the system leads to an abrupt temperature increase and to changes in the amplitude and phase dependences of the signal observed.

This work is supported by a Teledyne Research Assistance Grant, DOE, and the Center for Energy and Mineral Resources of Texas A\&M University.

\section{References}

[1] G. Da Costa and J. Calatroni, Appl. Opt. 17 (1978) 2381.

[2] J. Hartikainen, J. Jaarinen, and M. Luukkala, Can. J. Phys. 64 (1986) 1341.

[3] G. Da Costa and M. C. Coll, Physics Letters A 165 (1992) 153.

[4] S. A. Viznyuk and A. T. Sukhodolskii, Sov. J. Quantum Electron 18 (1988) 489.

[5] Al. A. Kolomenskii, Sov. J. Quantum Electron 19 (1989) 365. 